\title{
Tribo-Corrosion V 2016 - a return to Hyderabad
}

\section{Editorial}

\author{
Manish Roy \\ DMRL, Hyderabad, India
}

\author{
Margaret M. Stack \\ Tribology group, MAE, University of Strathclyde, Glasgow, UK
}

Tribo-Corrosion addresses the interactions between tribology and corrosion. The synergy between mechanical degradation i.e. due to tribology and chemical degradation from corrosion has led to the interdisciplinary science of Tribo-Corrosion. Following formation of the international Tribo-Corrosion network in the UK in 2001, and the European Federation of Corrosion working party on Tribocorrosion in 2003, the 1st international symposium on Tribo-Corrosion was held in Hyderabad, India in 2006. The 2nd, 3rd and 4th symposiums were held in Wiener Neustadt, (Austria) 2009, Atlanta, (USA) 2012 and Glasgow, (UK) respectively 2014. The 5th symposium returned to Hyderabad, India in 2001.

The 5th symposium was organised by Non Ferrous Materials Technology Development Center (NFTDC), Hyderabad (the first sponsors of the international conference series) with an objective of assembling experts from different areas on one platform, introducing the subject to young academics in the field and to others working in different areas of research and development, bring about stimulating discussion, understand the recent developments in this area and to plan a "routemap" on future strategy in the subject. The symposium was attended by more than 100 delegates from several countries.

The 1st paper of the special issue (UK) entitled "A critical review of the tribocorrosion of cemented and thermal sprayed tungsten carbide" concerning the wear corrosion performance of these WC based systems. A model was developed and relationship between wear mechanisms and environmental factors such as $\mathrm{pH}$ was established through a series of wear, electrochemical and wear corrosion experiments.

A group of Indian researchers presented the manuscript entitled "Effect of heat treatment on friction and abrasive wear behavior of WC-12Co and $\mathrm{Cr} 3 \mathrm{C} 2-25 \mathrm{NiCr}$ coatings". In this work, the effect of heat treatment on friction and abrasive wear behavior of WC-12Co and $\mathrm{Cr} 3 \mathrm{C} 2-25 \mathrm{NiCr}$ coatings at elevated temperature was investigated. The abrasive wear behavior was related to the phase transformations and variation in mechanical properties. The friction response of heat treated coatings with temperature was rationalized on the basis of the relative contributions of mechanical wear and oxidative wear. Abrasive wear regimes, transitions in wear mechanisms and failure modes were identified using severity of contact map. The paper entitled "Tribo-corrosion behavior of Ti6Al4V in artificial seawater at low contact pressures" (Austria) discusses tribo-electrochemical performance of Ti6Al4V in artificial seawater. The investigation was carried out under reciprocating sliding conditions. Depassivationrepassivation took place during sliding contact. An unusually higher coefficient of friction at $100 \mathrm{mN}$ load was correlated with a higher synergy between corrosion and wear and was linked with the initial surface roughness of the titanium alloy.

The 4th manuscript entitled "Tribological and cutting performance of TiAlCrN films with different $\mathrm{Cr}$ contents deposited with multilayered structure" by researchers from Portugal deals with the influence of $\mathrm{Cr}$ additions on the properties of $\mathrm{Ti}(\mathrm{Al}) \mathrm{N} / \mathrm{Cr}(\mathrm{Al}) \mathrm{N}$ multilayered films deposited be magnetron sputtering. High temperature tribological properties and cutting performance in real service drilling tests were evaluated and the results were compared with a monolayer Ti0.47A10.46N reference film. The drilling performance of coatings was assessed at cutting speeds in the range 50-200 rpm. Wear of the drills in different zones (chisel edge and flank edge) was mapped after each 15 holes. 
A 5th paper entitled "Tribo-corrosion study of nickel free, high nitrogen and high manganese austenitic stainless steel" (India) presents the electrochemical corrosion and tribocorrosion behaviors of nickelfree high nitrogen (HN SS) and high manganese containing austenitic stainless steel. The test was carried out in simulated body fluids such as Ringer's and artificial saliva solutions (ASS) using tribometer attached with the potentiostat. Type 316L stainless steel (SS) was used as reference alloy for the purpose of comparison. Open circuit potential (OCP) and potentiodynamic polarization techniques were used to examine the passivation and corrosion behavior of the investigated steels at room temperature. Pitting resistance of HN SS was found to be significantly higher than type 316L SS.

Finally, the manuscript entitled "Degradation mechanisms in martensitic stainless steels: wear, corrosion and tribocorrosion appraisal" by a European group provides a review of the published data from 2005 to present, related to wear, corrosion and tribo-corrosion of martensitic stainless steels. The main degradation mechanisms are found to be ploughing or abrasive wear for a dry contact, and pitting corrosion in the corrosive environment. It is hoped that this special issue will inspire more fundamental research in this area, more global collaborative work and stimulating discussion thus guiding future research in this fruitful research field.

We are grateful to Dr. Michel FILLON, Directeur de Recherche CNRS Institut Pprime and co-Editorin-Chief of 'Tribology International' for granting permission for a special issue and Prof. Hong. Liang, Professor, Department of Mechanical Engineering,Texas, A \& M University and co-Editor-in-Chief of 'Tribology International' for helping us in review process. Tribology International has been active in publishing the conference symposia and we appreciate their support.

We are thankful to all our sponsors, speakers, participants and organisers who contributed to making this event such a success. We are especially thankful to Dr. K. Balasubramanian, Director, NFTDC, for his constant help and encouragement and his vision. We also extend our sincere gratitude to all our reviewers who are listed below.

1) Albano Cavaleiro, (University of Coimbra, Portugal)

2) Andreas Pauschitz, (Austrian center of Competence for Tribology, Austria)

3) Manish Roy (Defence Metallurgical Research Laboratory, India)

4) Mark Godden Gee, (National Physical laboratory, UK),

5) Shoufan Cao, (Ecole Polytechnique Fédérale de Lausanne (EPFL), Switzerland)

6) S. Gokul Laskhmi, (Defence Metallurgical Research Laboratory, India)

7) Ana Eva Jimenez Ballesta, (Technical University of Cartagena, Spain)

8) Hongyu Gao, University of Saarbrucken, Germany

9) Stefano Mischler, (Ecole Polytechnique Fédérale de Lausanne (EPFL), Switzerland)

10) Prasanta Sahoo, (Jadavpur University, India)

11) Chunhua Ding, (China)

12) Sitaram Das, (Vellore Institute of Technology, India)

13) Philipp Niederhofer, (Deutsche Edelstahlwerke Specialty Steel Gmbh \& Co. KG

Research \& Development, Germany). 